\title{
Germinoma of the pituitary gland; a report of two
}

\section{cases}

\author{
J ANDREW, BE KENDALL, CD BROOK
}

From the Departments of Neurosurgery, Neuro-radiology and Paediatrics, the Middlesex Hospital, London, UK

SUMMARY Intracranial germinomas are usually situated in the pineal, but sometimes they arise in the infundibular region of the third ventricle (ectopic pinealoma) and may rarely extend down into the pituitary fossa. Two cases of germinoma arising within the pituitary gland and presenting with hypopituitarism, are described; no report of any similar cases could be found.

Intracranial germinomas usually arise in the pineal gland, when they may present with symptoms of raised intracranial pressure from obstructive hydrocephalus, impaired upward gaze, convergence, ptosis and pupillary disturbance (Parinaud syndrome), and even precocious puberty. Less frequently, they commence in the infundibular region of the third ventricle when diabetes insipidus may be the presenting symptom. From this situation, the tumour may rarely extend downwards into the pituitary fossa, although only four examples have been found in the literature..$^{1-3}$ We present two intrasellar germinomas which arose within the pituitary gland. The first extended through the suprasellar cisterns to elevate and splay apart the anterior recesses of the third ventricle; the second was confined entirely within the sella. A primary intrasellar mixed germ cell tumour has been reported, consisting of immature teratoma and dysgerminoma. ${ }^{4}$ It occurred in a 19 -year-old male, occasioning headaches and partial left IIIrd and VIth nerve palsies. Our two cases were germinomas without teratomatous features.

\section{Case reports}

Case 1 A girl aged 13 years, an asthmatic, is the third child of healthy, unrelated parents of above-average height. She grew normally until the age of 7 , following

Address for reprint requests: Dr BE Kendall, The Middlesex Hospital, Mortimer St, London W1N 8AA, UK

Received 19 June 1984 and in final form 10 October 1984. Accepted 12 October 1984 which her height deteriorated from the fiftieth to the tenth centile over a period of three years. At the age of 11 years, skull radiographs were normal and visual fields were full. Insulin tolerance test showed absence of growth hormone or gonadotrophins. Water deprivation test showed a rise in urine osmolarity to $515 \mathrm{mosmol} / \mathrm{kg}$ after 3 hours.

She was first seen at The Middlesex Hospital at the age of 10.8 years with a height of $131.8 \mathrm{~cm}$ and a bone age of $9 \cdot 1$ years. Although there were no abnormal neurological signs, the history suggested an intracranial lesion and she was admitted for investigation. Testing of the hypothalamo-pituitary axis with a combined stimulus of insulin-induced hypoglycaemia, thyrotrophin-releasing hormone and gonadotrophin-releasing hormone revealed absence of growth hormone and gonadotrophins; cortisol response was said to be adequate. T4 was $64 \mathrm{nmols} / \mathrm{l}$. There was no evidence of diabetes insipidus. Visual fields were still full; skull radiographs and CT scan (EMI 5005) were also normal. She was treated with growth hormone from 11.8 years of age without any improvement in growth rate.

At the age of 13 years, over a ten-day period she developed an incomplete right IIIrd nerve palsy with ptosis and diplopia. There was slight impaired up and down gaze and adduction of the right eye; the remaining movements were full. Visual field examination showed no defects and the optic discs appeared normal. There was no other abnormality. Pubertal ratings were all stage 1 for breast, and for axillary and pubic hair. Insulin tolerance again showed absent growth hormone and gonadotrophins, but at the beginning of the test, the cortisol was $374 \mathrm{nmol} / \mathrm{l}$ and at forty-five minutes was only $323 \mathrm{nmol} / \mathrm{l}$. Sleep studies showed growth hormone levels less than $2 \mathrm{mu} / \mathrm{l}$. T4 was $67 \mathrm{nmol} / \mathrm{l}$.

Plain radiographs now showed an irregularly enlarged sella. A CT scan (GE 8800), showed an enhancing mass asymmetrically enlarging the pituitary fossa, more on the right side. The mass stretched the cavernous sinus laterally 

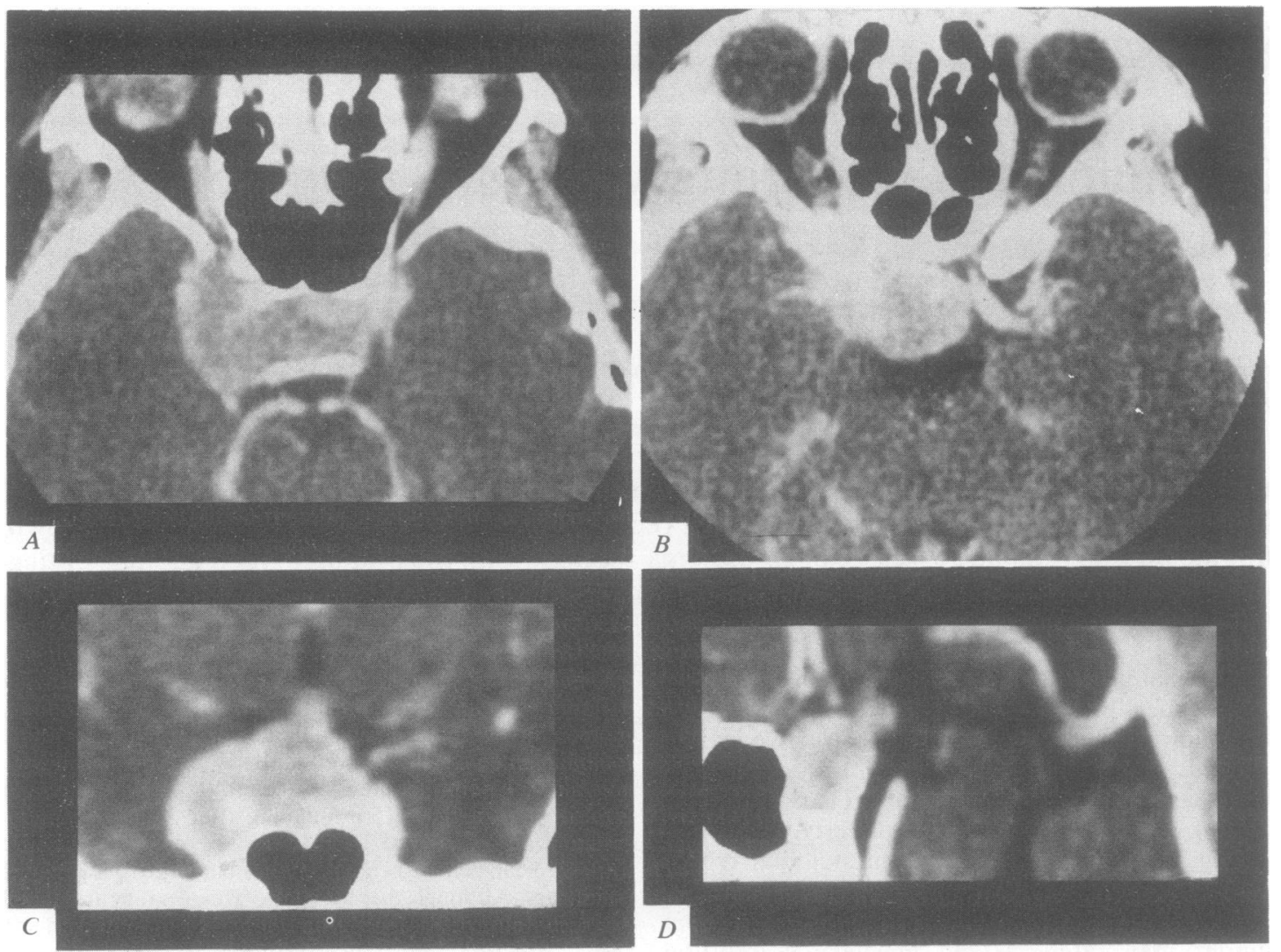

Fig (a) CT scan after intravenous contrast medium. (A) Axial section at level of pituitary fossa showing an enhancing mass enlarging the sella, more on the right side. It extends into the right cavernous sinus; the lateral border of the sinus impresses the temporal lobe and there is erosion of the medial border of the greater wing of the sphenoid with widening of the superior orbital fissure. (B) Axial section at level of the optic canals anteriorly and suprasellar cistern posteriorly. (C) Coronal reformatted section at level of midsella. (D) Reconstructed sagittal section. These show that the extension towards the cavernous sinus passes beneath the right internal carotid artery. The lobulated suprasellar extension elevates the first parts of the anterior cerebral arteries and optic chiasm and splays apart the anterior recesses of the third ventricle.

(b) Microphotograph of tumour of Case 1 (high power) to show large cells interspersed with small lymphocytes (see text). (Haematoxylin and eosin $\times 400)$.

and enlarged the right superior orbital fissure; suprasellar extension, more prominent on the right side, elevated and splayed the anterior recesses of the third ventricle $(\mathrm{fig}(a) A)$. Four-vessel angiography showed lateral displacement of the cavernous segment of the right internal carotid, elevation of the supraclinoid segments of both internal carotids and of the right posterior communicating artery, and of the first segment of the right and medial part of the left anterior cerebral arteries. There was no abnormal circulation. The radiological studies suggested an intrasellar tumour with lateral and supra-sellar extensions.

A small right frontal craniotomy was performed and the sella approached under the right frontal lobe. The right optic nerve was seen to be slightly elevated and encapsulated tumour projected laterally under its outer border, displacing the supraclinoid portion of the right internal carotid artery outwards. The tumour was then displayed between the optic nerves, and upward extension was seen to be slight. Aspiration through a fine needle was negative; the capsule was incised. The contents were soft and grey, and some normal-appearing pituitary was seen. Similar soft grey tissue was removed from between the right optic nerve and displaced internal carotid artery; posteriorly the capsule was now freed from the inferior end of a normalappearing pituitary stalk, which was divided at its attachment to the capsule. At the end of the operation, the only remaining tumour was thought to be in the wall of the right cavernous sinus. After operation the patient had polyuria and polydipsia, but a water deprivation test, in an 8 hour period, showed she did not have diabetes insipidus; these symptoms rapidly settled. Subsequently she received a course of deep X-ray therapy to the sellar region; there 


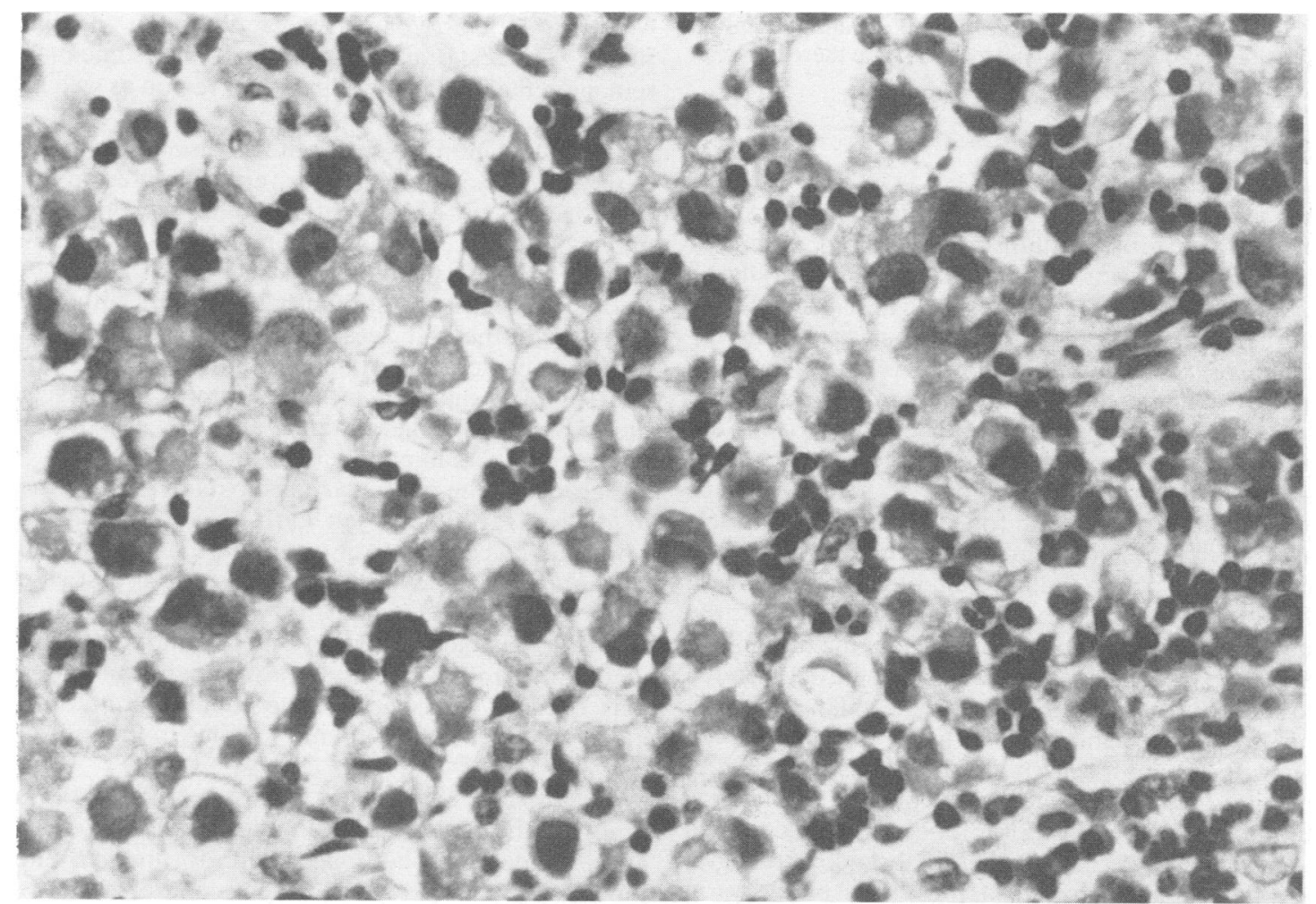

(b)

was a slight improvement to the IIIrd nerve paresis.

Histological examination of the tumour showed portions of adenohypophysis and a tumour composed of cells with large nuclei, prominent central nucleolus and clear cytoplasm interspersed with small lymphocytes. The appearance was typical of germinoma $(\mathrm{fig} b)$.

Further progress Five months after completion of radiotherapy to the sella, the patient developed headache, sickness and a right hemiparesis. CT scan revealed two enhancing tumour masses, one subfrontally mainly on the left side, and the other compressing the left parietal lobe. It was thought that these were secondary deposits by subarachnoid spread. The left sub-frontal tumour was excised and its histological appearance was identical to the primary intrasellar tumour. Because of the high dose of radiotherapy previously given further treatment was by chemotherapy alone, consisting of a regime of bleomycin, VP 16, vinblastine and cisplatin. Subsequent CT scan showed complete resolution of all the tumours and the child remains well 1 year later.

Case 2 A boy aged 13.4 years presented with a 5 year history of diabetes insipidus which, for the previous 3 years, had been treated with DDAVP. Earlier CT scan and skull radiographs at the referring hospital were normal. He now displayed poor growth and delayed puberty. Height was $142 \mathrm{~cm}$ (3rd centile), having been on the 50 th centile five years previously. Pubertal ratings were genitalia 2 , pubic hair 1 , testes $6 \mathrm{ml}$ right, $6 \mathrm{ml}$ left. Optic discs and visual fields were normal. Insulin tolerance test combined with hypothalamic releasing hormone stimulation of the pituitary (LHRH and TRH) showed absent growth hormone and attenuated cortisol responses to the hypoglycaemia. The response of LH and FSH to the releasing hormone was markedly attenuated and inappropriate for the stage of puberty. High resolution CT scan of the pituitary fossa showed a low-density lesion in the left lobe of the pituitary gland extending across to the midline. The left side of the pituitary fossa was slightly larger than the right, but there was no evidence of any suprasellar or lateral extension. The appearances of the pituitary fossa scan were consistent with a micro-adenoma. High resolution CT scan of the pineal and hypothalamic regions excluded any tumour mass in these areas.

In view of the abnormal endocrinology and poor growth, trans-sphenoidal hypophysectomy was performed by $\mathrm{Mr}$ RA Williams. At operation only a small proportion of the pituitary fossa was occupied by normal tissue, the remainder being tan-coloured tumour which was removed completely.

Histological examination of the tumour showed the appearance of a germinoma without teratomatous features; identical with the tumour in case 1. 
He was subsequently given a course of radiotherapy to the sella, and the cranio-spinal axis. To date there has been no recurrence after 15 months.

\section{Discussion}

Our first case resembled that of Page et al, ${ }^{4}$ in that the tumour arose within the sella but extended superiorly, anterior to the chiasm and laterally to involve the right cavernous sinus, displacing the supraclinoid portion of the internal carotid artery laterally. As in their case, there was no preoperative diabetes insipidus, although our patient showed pan-hypopituitarism. They quote from the literature six cases of mixed-germ tumours extending from the infundibulum into the sella and diabetes insipidus occurred in four. All had enlarged sellas, four had oculomotor disturbance and five had pituitary-endocrine failure, although one of these showed precocious puberty. In all of these cases, the tumour was believed to have arisen in the infundibular region of the third ventricle and to have extended down through its floor to reach the sella. Although our first patient showed pan-hypopituitarism, even when the tumour was large there was no diabetes insipidus; this suggested that neither the infundibulum nor the posterior lobe of the gland had been significantly damaged. The absence of diabetes insipidus or disturbance of the visual pathways in our patient, suggests that the tumour had not arisen in the more common position in the infundibular region of the third ventricle and extended through its floor to reach the pituitary gland.

Our second patient presented with diabetes insipidus and only later with pan-hypopituitarism; it is, therefore, likely that the tumour commenced in the posterior lobe and only later involved the anterior lobe. The findings of the high resolution CT scan, and at surgery, confirm that the tumour was confined to the pituitary and without any evidence of extrasellar extension.

Both these tumours were histologically identical with pineal and suprasellar germinomas which Russell believed arose from germ cells which migrate widely in the embryo and then settle in the gonadal ridges. ${ }^{5}$ The rest of the cells disappear but some may remain in the pineal and suprasellar region as well as in other locations.

Though adenoma is by far the commonest tumour of the pituitary gland, it is very rarely manifest in the first decade of life. Pituitary tumours constitute under one per cent of intracranial tumours in children and these usually involve teenagers. Demonstration of a mass indistinguishable from a pituitary adenoma in the first decade of life should therefore lead to consideration of an alternative diagnosis. In this situation diabetes insipidus may even suggest the possibility of germinoma and the search for tumour markers may help confirm the diagnosis.

Because of the particular sensitivity of germinoma to deep $\mathrm{x}$-ray therapy an early diagnosis may be rewarded by complete regression of the tumour and clinical cure. However the progress of our first case illustrates the necessity for whole cranio-spinal irradiation as required for primitive tumours such as medulloblastoma, when subarachnoid dissemination may occur. Their sensitivity to chemotherapy may make this the first treatment of choice in the future.

We thank Dr P Dhillan and Professor N Woolfe who reported the pathological findings of the first case, and provided the photomicrograph for fig $(a) B$ and Dr D S Brew who reported the second case.

\section{References}

${ }^{1}$ Horrax G, Wyatt JP. Ectopic pinealomas in the chiasmal region. Report of three cases. $J$ Neurosurg 1947;4:309-436.

${ }^{2}$ Kageyama N, Belsky R. Ectopic pinealoma in the chiasm region. Neurology (Minneap) 1961;11:318-27.

${ }^{3}$ Ghatak NR, Hirano A, Zimmerman HM. Intrasellar germinoma: a form of ectopic pinealoma. J Neurosurg 1969;31:670-5.

${ }^{4}$ Page RB, Plourde V, Coldwell D, Heald UI, Weinstein J. Intrasellar mixed germ cell tumour. J Neurosurg 1983;58: 766-70.

${ }^{5}$ Russell DS. The pinealoma; its relationship to teratoma. J Pathol Bacteriol 1944;56:145-50. 